\title{
GILBERT LEWIS E O CENTENÁRIO DA TEORIA DE LIGAÇÃO POR PAR DE ELÉTRONS\#
}

\author{
Carlos A. L. Filgueiras \\ Departamento de Química, Universidade Federal de Minas Gerais, 31270-901 Belo Horizonte - MG, Brasil
}

Recebido em 21/06/2016; aceito em 01/09/2016; publicado na web em 29/09/2016

\begin{abstract}
GILBERT LEWIS AND THE CENTENNIAL OF THE ELECTRON PAIR THEORY OF CHEMICAL BONDING. The year 2016 marks the centennial of the first approach to describe all types of chemical bonds by means of a unified theory, that of the electron pair, as proposed by the American chemist Gilbert Newton Lewis (1875-1946). Lewis probably became the best known chemist of the twentieth century. Any highschool student anywhere has heard of him and uses concepts such as Lewis acids and bases. His seminal ideas, albeit modified with time, remain a source of inspiration as the basis of much that came later. Lewis established his theory in a series of articles, the most important dating from 1916. His life and achievements are the stuff of much study and debate, as this essay aims to show.
\end{abstract}

Keywords: Gilbert Lewis; chemical bonding; centennial of electron pair theory, bonding theory.

\section{INTRODUÇÃO}

Alguns poucos químicos estabeleceram, ao longo da história, conceitos e teorias que vieram a ter uma influência profunda na ciência, desafiando o tempo, mesmo que vários aspectos de suas teorias se tenham modificado com o passar dos anos. Assim, Lavoisier, no último quartel do século XVIII, sepultou a antiga teoria dos quatro elementos, que vinha desde a Grécia antiga, ao demonstrar que a água, longe de ser elementar, é um composto que pode ser facilmente resolvido em seus constituintes, estes sim elementares, o oxigênio e o hidrogênio. Tampouco o ar é elementar, como também o demonstrou Lavoisier, sendo constituído por uma mistura de gases. Estes são aspectos basilares da nova química estabelecida pelo químico francês, e marcam o que se considera o início da química moderna. ${ }^{1-3}$

Na década seguinte à morte trágica de Lavoisier, John Dalton propôs sua teoria atômica, pondo pela primeira vez em bases operacionais o conceito de átomo, que ocupara as mentes de tantos filósofos por mais de dois milênios. A partir de Dalton, foi possível trabalhar quantitativamente os átomos, determinando suas massas e estabelecendo relações estequiométricas em bases sólidas, tirando a química de seu estado eminentemente descritivo. Isto foi possível mesmo sem que se tivesse uma demonstração experimental direta da existência dos átomos, o que só se logrou no início do século XX. O próprio Dalton foi um dos pioneiros desta nova atitude, determinando pesos atômicos e estabelecendo a lei das proporções múltiplas. ${ }^{4}$

Pouco mais de um século depois, Gilbert Newton Lewis estabeleceu a primeira teoria de ligação química abrangente, que agrupava num único conceito todos os tipos de ligação química, permitindo mostrar relações entre substâncias iônicas, covalentes, moleculares e mesmo metálicas, até então sem qualquer nexo conceitual comum. Ora, o objeto de estudo da química é exatamente a natureza da ligação entre os átomos dos elementos. Estes tendem a interagir, formando compostos os mais variados, num processo de formação e ruptura de ligações, que é a preocupação central desta ciência. Por isso se pode apreciar a importância da contribuição de Lewis, e é por isso que ele pode ser posto ao lado dos dois antecessores mencionados anteriormente. De acordo com Sason Shaik, enquanto Lavoisier e

*e-mail: calfilgueiras@gmail.com

"This paper is part of the PubliSBQ Special Issue in honor of the late Prof. Angelo da Cunha Pinto.
Dalton empreenderam uma "revolução composicional" na química, Lewis encabeçou uma "revolução estrutural".

Muito se discute que não existiria uma filosofia química, ao contrário do que sucede na física ou na biologia, que debatem temas como a gênese do universo ou a natureza da vida. Ora, assim como Lavoisier e Dalton, Lewis foi um verdadeiro filósofo químico, e é isto que se quer ressaltar aqui, pois foi o primeiro a introduzir na química uma nova forma ampla de pensar sobre como e por que os átomos se ligam para formar compostos, isto é, o problema fundamental da química, como se salientou acima. Mesmo que o entendimento sobre a natureza da ligação química tenha evoluído extraordinariamente em um século, os químicos são devedores a Lewis de ideias originais e fecundas, que moldaram profundamente boa parte da química que se seguiu.

\section{VIDA}

Gilbert Newton Lewis nasceu em 1875 em Weymouth, Massachusetts, filho do advogado Francis Wesley Lewis e de Mary Burr Lewis, e morreu em 1946 em seu laboratório de Berkeley. A família se mudou para a cidade de Lincoln, no estado de Nebraska quando ele tinha nove anos. Ele havia aprendido a ler sozinho aos três anos de idade. Na adolescência entrou para a Universidade de Nebraska, mas depois transferiu-se para Harvard, onde se graduaria em 1896. Há divergências em seus biógrafos quanto à data de sua ida para Harvard, apontada como tendo ocorrido em $1892^{7}$ ou $1893^{6}$. Apesar de ter também muito interesse em economia, graduou-se em Química em 1896. ${ }^{6-8}$ Em 1898 completou seu mestrado em Harvard, com a dissertação intitulada "O elétron e a molécula". ${ }^{9}$ Note-se que a descoberta do elétron por J.J.Thomson havia ocorrido apenas no ano anterior. Lamentavelmente, como conta seu último ex-aluno Michael Kasha, a dissertação de Lewis desapareceu e Kasha diz que, apesar de ter visto o exemplar de Lewis em seu gabinete, após sua morte não conseguiu localizar nenhum exemplar da dissertação, por mais que buscasse, mesmo nas bibliotecas de Harvard. ${ }^{9}$ Seria muito interessante conhecer o teor desse texto, uma vez que o assunto diz respeito àquilo por que Lewis viria se tornar mais conhecido. Em 1899 ele receberia o $\mathrm{PhD}$ por Harvard, trabalhando sob a orientação de Theodore William Richards, que seria o primeiro químico americano a receber o Prêmio Nobel, em 1914, pelo desenvolvimento de métodos para a determinação exata de pesos atômicos. ${ }^{10}$ Sua tese de 
$\mathrm{PhD}$ se intitulou "Algumas relações eletroquímicas e termoquímicas de amálgamas de zinco e cádmio", e gerou seu primeiro artigo, em coautoria com o orientador. ${ }^{11}$ Como dizem os autores no artigo, seu propósito foi sobretudo descrever um método conveniente para medir a força eletromotriz diretamente de uma célula eletroquímica, mostrando que amálgamas de cádmio e de zinco em baixas concentrações obedecem as leis para soluções diluídas, e permitem também estudar suas propriedades termodinâmicas. Depois de mais um ano como instrutor em Harvard, Lewis recebeu uma bolsa de estudos para estagiar por um semestre com Wilhelm Ostwald em Leipzig e outro semestre com Walther Nernst em Göttingen. As personalidades desses dois químicos alemães não poderiam ser mais diferentes. Enquanto a estada em Leipzig fez Lewis se sentir bem e bastante estimulado, em virtude da atitude encorajadora de Ostwald, o estágio em Göttingen fê-lo sentir-se miserável, em consequência da rudeza e agressividade de Nernst. ${ }^{8}$ Ao retornar aos Estados Unidos passou mais três anos como instrutor em Harvard e foi nesse período, a partir de 1902, que ele começou a desenvolver suas ideias a respeito do octeto eletrônico e seu papel na formação de ligações químicas, escrevendo um memorando que permaneceu inédito por muito tempo. Anos depois, em seu livro Valence and the Structure of Atoms and Molecules ${ }^{12}$, de 1923, ele próprio revelaria:

"No ano de 1902 (enquanto estava tentando explicar a uma classe elementar de química algumas das ideias envolvidas na lei periódica), ficando interessado na nova teoria do elétron, e combinando esta ideia com aquelas implicadas na classificação periódica, formei a ideia da estrutura do átomo que, embora contivesse certas imperfeições, desde então considerei como representando essencialmente o arranjo de elétrons no átomo. $\mathrm{Na}$ Figura 3 (do livro) se reproduz uma parcela de meu memorando de 1902 que ilustra a teoria.

Os aspectos principais desta teoria de estrutura atômica são os seguintes:

(1) Os elétrons num átomo estão arranjados em cubos concêntricos.

(2) Um átomo neutro de cada elemento contém um elétron a mais que um átomo neutro do elemento imediatamente precedente.

(3) O cubo de 8 elétrons é alcançado nos átomos dos gases raros, e este cubo se torna de certa maneira o caroço (kernel) em torno do qual se constrói o cubo maior de elétrons do período seguinte.

(4) Os elétrons de um cubo externo incompleto podem ser cedidos a outro átomo, como no $\mathrm{Mg}^{++}$, ou suficientes elétrons podem ser retirados de outros átomos para completar o cubo, como no $\mathrm{Cl}$, dando conta da 'valência positiva ou negativa.'

De acordo com a ideia de Mendeleev de que o hidrogênio éo primeiro membro de um período completo, supus erroneamente que o hélio tivesse uma camada de oito elétrons. Com relação à disposição da carga positiva que balanceava os elétrons no átomo neutro, minhas ideias eram muito vagas; acredito que me inclinei naquela época em direção à ideia de que a carga positiva era também formada por partículas discretas, cuja localização determinava a localização dos elétrons.

Estas hipóteses relativas ao arranjo de elétrons no átomo, embora tivessem sido discutidas livremente com meus colegas e em minhas aulas, não tiveram nenhuma publicidade adicional."

A Figura 1 a seguir reproduz o desenho mencionado por Lewis. Em 1904 Lewis foi nomeado para os cargos de superintendente de pesos e medidas das Filipinas e químico do Birô de Ciência em Manila. As Filipinas eram então um protetorado americano, tomado à Espanha depois da derrota desta na Guerra Hispano-Americana

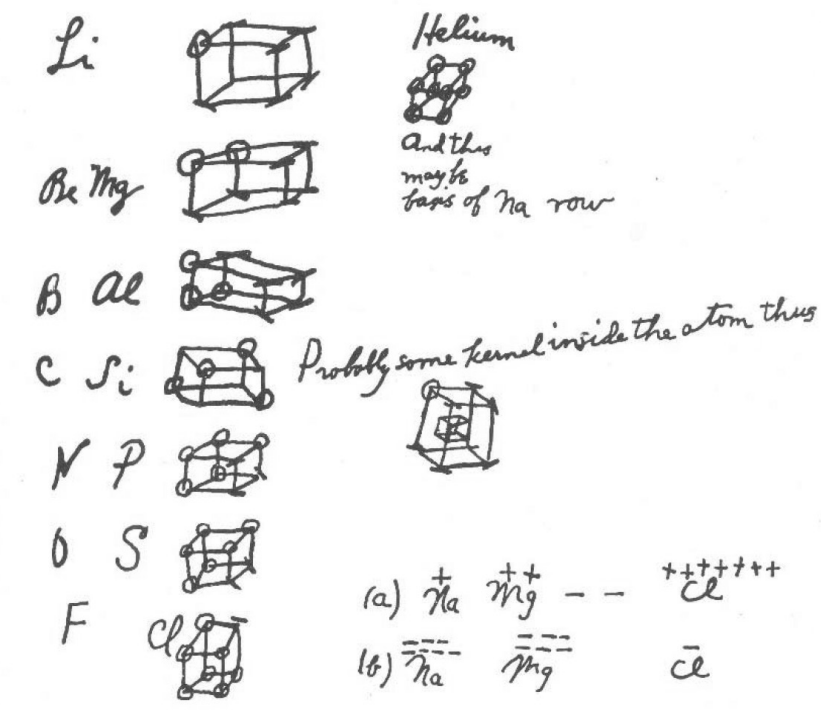

$\mathrm{NaCl}$

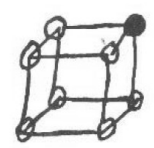

Figura 1. Desenhos de Lewis do memorando de 1902, reproduzidosem seu livro "Valence", de 1923

de 1898. Lewis levou consigo para as Filipinas um único livro, a Physikalische Chemie de Nernst, usando-o para corrigir seus "erros". 9 A inimizade entre Lewis e Nernst pode ter contribuído para que Lewis jamais tivesse ganhado o Prêmio Nobel. ${ }^{8}$ Das Filipinas ele trouxe o hábito de fumar charutos o tempo todo. Em 1905 Lewis retornou aos Estados Unidos e foi para o Massachusetts Institute of Technology, onde trabalhou estreitamente com Arthur Amos Noyes. Sua produção na área de termodinâmica foi extraordinária, de sorte que em 1912 ele já era professor titular e diretor de pesquisa no MIT. Nesse mesmo ano Lewis se casou com Mary Hinckley Sheldon, filha de um professor de línguas romances em Harvard, com quem teve dois filhos e uma filha. ${ }^{6}$ Sua reputação fez com que ele fosse convidado ainda em 1912 a assumir a direção do Instituto de Química da Universidade da Califórnia em Berkeley. Lá ele reorganizou toda a química e tornou Berkeley uma das instituições líderes nessa ciência. Em Berkeley ele permaneceu até o fim de sua vida, desenvolvendo uma carreira de enorme brilho em várias áreas científicas. A liderança de Lewis era tão positiva que, como disse seu colega Joel Hildebrand, "o departamento se tornou muito maior que a soma de seus membros individuais". ${ }^{7} \mathrm{O}$ chefe continuamente estimulava a iniciativa e a criatividade de professores e estudantes, fazendo com que o ambiente acadêmico fosse o mais frutífero e agradável possível. Ao recrutar jovens colaboradores, eles eram designados instrutores e professores de química, e não de uma de suas subdivisões, como relata Hildebrand. ${ }^{7}$ Seu famoso livro de 1923, Valência e a estrutura de átomos e moléculas ${ }^{12}$, surgiu dos seminários de discussão desses temas com colegas e alunos. Por isso, sua generosa introdução ao livro diz: "a meus colegas e estudantes da Universidade da Califórnia, sem cuja ajuda este livro não teria sido escrito. Em nossos muitos anos de discussão dos problemas de estrutura atômica e molecular, algumas das ideias aqui apresentadas surgiram do grupo, ao invés de um indivíduo; de modo que, num certo sentido eu sou apenas o editor desse grupo". ${ }^{13}$

Durante a Primeira Guerra Mundial Lewis deixou provisoriamente seu posto para trabalhar no esforço de guerra como cientista na Europa, a partir de dezembro de 1917, em virtude do perigo representado pela guerra química que então se praticava. Ele organizou a 
Escola de Defesa contra Gases da Força Expedicionária Americana, que treinava 200 oficiais por semana para o exército americano, o que causou um enorme decréscimo nas baixas de ataques por gases. Ele foi condecorado pelos Estados Unidos com a Distinguished Service Medal e pela França, que lhe outorgou a Legião de $\mathrm{Honra}^{7}$, e deixou o serviço militar com o posto de tenente-coronel. Após a guerra Lewis iniciou um longo e frutífero trabalho em termodinâmica com seu ex-aluno Merle Randall, um de cujos resultados foi a publicação pelos dois do famoso livro Termodinâmica e a energia livre de substâncias químicas, em 1923, com edições posteriores. ${ }^{14}$

Em sua vida profissional ele orientou mais de uma centena de doutorados e vários de seus alunos ganharam o Prêmio Nobel, como Glenn Seaborg e Melvin Calvin. Ele próprio foi indicado 35 vezes para o prêmio, sem jamais recebê-lo. ${ }^{8}$ Possivelmente nenhum orientador de teses teve tantos orientados seus a receber o galardão da Academia Sueca. Como exemplo, Harold Urey obteve em 1922 seu doutorado em Berkeley, onde havia estudado termodinâmica com Lewis, e em 1931, já como professor de química em Columbia, anuncia a descoberta do deutério, que lhe valeria o Prêmio Nobel em 1934. Durante esses três anos Lewis e colaboradores publicaram 26 artigos sobre o deutério e inúmeros aspectos da água pesada. ${ }^{8}$ Todavia, Lewis nem sequer foi lembrado como co-recipiente do prêmio com Urey. Talvez essa omissão tenha contribuído para que Lewis renunciasse a sua condição de membro da National Academy of Sciences dos Estados Unidos em 1934. ${ }^{15}$

Lewis recebeu inúmeras outras honrarias ao longo da vida, entre as quais serão mencionadas apenas algumas, como os títulos de doutor honoris causa das universidades de Chicago, Liverpool, Madrid, Pennsylvania e Wisconsin. Também foi eleito como membro honorário de várias entidades, como a Royal Institution of Great Britain, a Royal Society, a Chemical Society of London, a Academia das Ciências da Índia, a Academia Sueca, a Academia da Dinamarca e o Franklin Institute of Pennsylvania. Recebeu igualmente as medalhas Nichols, Gibbs, Davy, Arrhenius, Richards e da Society of Arts and Sciences. ${ }^{7}$

O caráter introvertido e pouco gregário de Lewis pode ter contribuído para que ele nunca tivesse recebido o Prêmio Nobel. Ele era arredio e pouco dado a viajar, apesar de sua prolífica produção, seja de artigos ou discípulos. Sua inimizade com Irving Langmuir (1881-1957, Prêmio Nobel em 1932), o extrovertido químico de quem Lewis suspeitava querer apropriar-se de suas ideias a respeito da natureza da ligação química, contribuiu para o que muitos dizem ter sido o caráter depressivo de Lewis. ${ }^{16}$

Lewis foi indicado para o Prêmio Nobel de 1922 a 1944. A primeira indicação deveu-se a seu antigo orientador de doutorado Theodore Richards, por sua contribuição à termodinâmica química e à teoria de ligação química. Já em 1924, Svante Arrhenius, consultado sobre sua contribuição para o conhecimento da ligação química, declarou-a “insignificante", e exaltou, ao contrário, a contribuição de Langmuir, o rival de Lewis. Talvez tenham pesado algumas críticas anteriores de Lewis a Arrhenius, o qual, todavia, no final da vida (Arrhenius morreria em 1927), não se mantinha tão atualizado com a ciência. ${ }^{8}$ Após receber nove indicações no ano de 1926, o relatório à Academia Sueca é redigido por Theodor Svedberg, que recomenda ser prematuro atribuir o prêmio a Lewis naquele momento. O curioso é que quem o recebeu em 1926 foi o próprio Svedberg. ${ }^{8}$ Como escreveu Coffey, "em retrospecto, o trabalho de Lewis sobre o papel do par de elétron na química foi sua conquista científica mais significativa, particularmente se seu trabalho sobre ácidos e bases e em fotoquímica forem examinados como parte do mesmo empreendimento como sua descoberta da ligação covalente". O mesmo autor diz ainda que a atitude prevalente entre os químicos suecos após a revolução quântica era claramente desfavorável a modelos não-matemáticos simplificados baseados no par eletrônico, sem levar em conta a utilidade que eles pudessem ter em outras áreas da química. Outros físico-químicos, todavia, como Louis Hammett e Christopher Ingold, ambos os quais indicaram Lewis para o prêmio, não concordavam com este ponto de vista. Coffey acrescenta ainda que a grande ironia é que as maiores contribuições de Lewis beneficiaram a química orgânica, disciplina em que ele havia recebido um D como conceito em seu curso de graduação. ${ }^{17}$ Se vivesse mais alguns anos, talvez Lewis tivesse compartilhado o Prêmio Nobel de 1954 com Linus Pauling, que o tinha como um importante predecessor. De fato, o prêmio de Pauling, que reconhecia seu papel no tratamento quântico de ligações direcionais, devia muito ao papel de Lewis em abrir esse caminho. ${ }^{17}$

Uma lenda persistente diz que Lewis se teria suicidado por envenenamento no laboratório em virtude de uma série de fatores, como seu temperamento depressivo, por achar que seu tempo como pesquisador de ponta já pertencia ao passado e por ter sido deixado de lado na concessão dos Prêmios Nobel. Seu último doutorando, Michael Kasha, que o encontrou morto no laboratório na tarde de 23 de março de 1946, conta, todavia, uma história diferente em artigo publicado em 1984. Lewis, um grande perito em lidar com baixas temperaturas e sistemas de vácuo, estava na época trabalhando com cianeto de hidrogênio liquefeito. Seu interesse se deveu a ele ter lido na literatura que o $\mathrm{HCN}$ líquido pode variar sua constante dielétrica por um fator de até 100, dependendo da temperatura. Esta propriedade, relata Kasha, levou Lewis a dizer-lhe: "este seria um meio bastante interessante para testar o efeito da constante dielétrica na cor das tinturas". Lewis havia trabalhado bastante na fotoquímica relacionada à variação de cor das tinturas orgânicas. Kasha narra que, ao passar pelo laboratório às 14 horas daquele sábado, não viu o professor e sentiu um forte cheiro de cianeto. Ao entrar, deparou-se com Lewis estendido no chão e um líquido borbulhando na capela, desprendendo o intenso odor de cianeto. Imediatamente ele chamou outros pesquisadores e, cobrindo o nariz, quebrou a vidraça da janela com um tijolo e jogou bastante bicarbonato sobre o líquido borbulhante na capela. Lewis foi levado imediatamente ao hospital da universidade, mas já chegou morto. Kasha afirma ainda que uma autópsia revelou que a causa da morte havia sido um infarto agudo do miocárdio. Kasha conclui que depois do ataque cardíaco a pressão no frasco com cianeto líquido que estava no Dewar havia aumentado, fazendo com que o líquido em ebulição se derramasse pela capela. Kasha também diz que não havia no cadáver de Lewis as marcas características da cianose, que são um arroxeamento das unhas e dos lábios. ${ }^{9}$ Todavia, ao contrário do que afirma Kasha, a realidade é que não foi feita autópsia no cadáver, o que introduz mais um elemento de dúvida. Kasha também diz que antes de sua morte no laboratório, Lewis havia ido almoçar com um "distinto visitante", sem dizer quem ele era. Contudo, em entrevista dada a Patrick Coffey, o autor de Cathedrals of Science, em 2004, Kasha se lembrou de quem era o "distinto visitante": ninguém menos que Irving Langmuir. Coffey relata que foi à Biblioteca do Congresso, num lance detetivesco, e consultou os papéis de Langmuir, que lá se acham. Para sua surpresa descobriu que em 23 de março de 1946, no dia da morte de Lewis, Berkeley havia conferido a Langmuir um título honorário. Este também havia sido convidado a proferir uma série de conferências na universidade. A premiação ocorreu no período da manhã e Lewis não esteve presente. Aparentemente, segundo Coffey, Wendell Latimer e Joel Hildebrand arranjaram um almoço privado na tentativa de aproximar os dois eminentes químicos. Nada se sabe do que pudesse ter ocorrido naquele almoço. O certo é que pouco depois Gilbert Lewis jazia morto em seu laboratório.

A ausência dos sintomas de envenenamento por cianeto no cadáver de Lewis, como testemunharam Kasha e outros, pode ser um indício de que a morte não se deveu a envenenamento, mas poderia ter sido causada por algum problema cardíaco em decorrência do 
constrangimento e da tensão sofridos por Lewis ao ter que conviver por alguns momentos com seu rival.

Lewis passou à história da ciência sobretudo por duas áreas importantes em que muito contribuiu: a teoria da ligação química e a termodinâmica química, área em que introduziu uma série de conceitos, como atividade e fugacidade. No final da vida teve grande destaque seu papel no desenvolvimento da fotoquímica. Ele foi o autor de muitos trabalhos experimentais envolvendo o óxido de deutério, e foi também o descobridor, em 1924, do dímero da molécula de oxigênio, $\mathrm{O}_{4}$, que se obtinha pela dissolução de oxigênio em nitrogênio líquido. À medida que a concentração de $\mathrm{O}_{2}$ paramagnético aumentava, a concentração da molécula diamagnética $\mathrm{O}_{4}$ também aumentava, até que se estabelecia um equilíbrio, como mostravam seus dados de susceptibilidade magnética.

De fato, Lewis publicou em 1924, em J. Amer. Chem. Soc. um artigo intitulado "O Magnetismo do Oxigênio e a Molécula de $\mathrm{O}_{2}$ ". ${ }^{18}$ Neste artigo ele combina aspectos experimentais e teóricos, e começa por afirmar: "uma das propriedades características do oxigênio é seu pronunciado paramagnetismo. Isto distingue o oxigênio molecular tão fortemente de outros compostos em que se supõe o oxigênio ligado por uma ligação dupla que eu concluí recentemente que não há qualquer ligação dupla na molécula de $\mathrm{O}_{2}$. Ao contrário, supus que os dois elétrons que se pensava constituíssem a segunda ligação estão na realidade separados, de modo que cada átomo tenha um elétron desemparelhado, de acordo com a fórmula” (dada na Figure 2).

\section{:Ọ : Ö:}

Figura 2. Estrutura proposta por Lewis para a molécula de $\mathrm{O}_{2}$

De fato, "o oxigênio tem as propriedades de uma molécula com elétrons desemparelhados, pois ele tem uma cor apreciável, e uma reatividade muito maior do que comumente se lhe atribui." A partir daí prevê a possibilidade de dimerização da molécula, dando o tetraoxigênio, que ele passa a discutir. Nesse período pré-quântico da química, de fato não se poderia esperar uma descrição da molécula de dioxigênio como a entendemos hoje, mas a honestidade intelectual de Lewis ao interpretar seus dados experimentais é notável. Como escreveu Linus Pauling em 1984, a respeito da reação de dimerização do dioxigênio para dar o tetraoxigênio: "ele conseguiu justificar os valores experimentais da susceptibilidade magnética das soluções de oxigênio (líquido) em nitrogênio (líquido), pela suposição de que há um equilíbrio entre moléculas paramagnéticas de dioxigênio e as moléculas diamagnéticas de tetraoxigênio, $\mathrm{O}_{4}$. Dos valores da susceptibilidade magnética ele foi capaz de obter a variação da energia livre padrão de Gibbs e a variação de entalpia da reação." 19

A existência do dímero de $\mathrm{O}_{2}$, contudo, permaneceu em suspenso até o século XXI, por falta de uma comprovação direta de sua existência. Nos últimos anos, contudo, as ideias de Lewis geraram uma torrente de trabalhos de enorme interesse. Em 2001 um grupo italiano conseguiu determinar experimentalmente a existência do chamado oxozônio, $\mathrm{O}_{4}$, por espectrometria de massas do íon $\mathrm{O}_{4}{ }^{+}{ }^{20}$

A literatura recente tem um grande número de artigos sobre os alótropos mais pesados do oxigênio, tanto experimentais como teóricos, que mostram, por exemplo, a existência da forma sólida $\mathrm{O}_{8}$, chamada de oxigênio vermelho, em pressões muito altas. Quanto ao alótropo $\mathrm{O}_{4}$, ele é um cluster que pode apresentar duas estruturas calculadas distintas, uma cíclica, formando um quadrilátero reverso, com simetria $\mathrm{D}_{2 \mathrm{~d}}$, e outra trigonal plana, com simetria $\mathrm{D}_{3 \mathrm{~h}}$. Esta última é muito interessante, por completar uma sequência homóloga que engloba $\mathrm{BO}_{3}{ }^{3-}, \mathrm{CO}_{3}{ }^{2-}$ e $\mathrm{NO}_{3}{ }^{-}$, além de ser semelhante ao $\mathrm{SO}_{3}{ }^{21,22}$

A catolicidade dos interesses de Lewis está demonstrada nos inúmeros assuntos sobre os quais ele publicou, como economia ou a causa das glaciações. Um artigo seu, intitulado "A Termodinâmica da Glaciação" foi publicado postumamente em Science, como menciona Kasha. ${ }^{9}$

Lewis foi um pesquisador que não reconhecia barreiras epistemológicas artificiais. Nas primeiras décadas do século XX, químicos e físicos raramente se falavam, à exceção de alguns cientistas fora do padrão. Isso foi o que levou, por exemplo, à demora dos químicos em tomar conhecimento da teoria do campo cristalino, formulada por um físico, Van Vleck. Lewis, um excelente matemático, foi o primeiro cientista americano a se ocupar da teoria da relatividade de Einstein, e em 1908-9 publicou vários artigos sobre o tema. ${ }^{23} \mathrm{O}$ tema retornaria em 1926, em seu livro intitulado The Anatomy of Science, que também apresenta um pronunciado pendor filosófico. ${ }^{24}$

Em seus últimos anos ele confessaria a Michael Kasha que as moléculas orgânicas se tinham tornado a alegria de seus dias, apesar de, durante a maior parte da vida, ele ter detestado a química orgânica porque havia recebido um conceito ruim num curso dessa disciplina quando estudante em Harvard. ${ }^{9}$

Lewis também é responsável pela palavra fóton e seu uso em ciência, em substituição à antiga expressão quantum de luz. Embora a palavra fóton já tivesse sido usada antes por outros pesquisadores, notadamente nos campos de psicologia e fisiologia ${ }^{25}$, a introdução do termo por Lewis em 1926, num artigo em Nature, foi o que acabou adotado universalmente. ${ }^{26}$ Todavia, Lewis considerava o fóton mais uma partícula subatômica que uma unidade de energia.

\section{A TEORIA DE LIGAÇÃO ELETRÔNICA}

A Teoria de Lewis da Ligação Química fundamentada sobre o conceito de par de elétrons foi desenvolvida principalmente em três artigos seminais: o primeiro, publicado em J. Amer. Chem. Soc. em 1913, intitula-se "Valência e Tautomerismo"27, e contém o germe do que viria a seguir. Neste artigo, Lewis adota os termos "número de valência" e "número polar", designando o que chamamos de valência e número de oxidação, respectivamente. Em suas palavras, o número de valência é "o número de posições, ou regiões ou pontos no átomo em que ocorre a ligação a pontos correspondentes em outros átomos"; já o número polar é "o número de elétrons negativos que um átomo perdeu". Numa nota de rodapé ele acrescenta a propósito dos compostos polares e não-polares: "não se deve supor que um dado composto corresponda totalmente e sempre a qualquer um dos dois tipos". Mais adiante acrescenta: "Aos compostos polares e não-polares podemos adicionar um terceiro, o metálico. No primeiro tipo os elétrons ocupam posições fixas no átomo. No segundo, os elétrons se movem livremente de átomo a átomo dentro da molécula. No terceiro tipo, ou metálico, o elétron é livre de se mover fora da molécula." O último parágrafo deste artigo novamente enfatiza a convicção de Lewis: "todos os compostos químicos conhecidos podem ser agrupados nas três classes: não-polar, polar e metálico, exceto quando o mesmo composto possa cair em parte ou temporariamente em dois desses grupos".

O segundo artigo, também publicado em J. Amer. Chem. Soc., em 1916, intitula-se "O átomo e a molécula"28, e é o mais importante deles. Nele, Lewis começa por discutir a necessidade de considerar uma teoria da estrutura atômica, a qual ele já utilizava havia alguns anos na interpretação de fenômenos químicos, mas só então resolvera publicar. A diferença fundamental entre os compostos polares e não-polares é que, "nos primeiros um ou mais elétrons são ligados por forças suficientemente fracas, de modo que possam tornar-se separados de suas posições primitivas nos átomos e, no caso extremo, passam completamente para outro átomo." Já nos compostos chamados de não-polares "os elétrons pertencentes ao átomo individual 
são seguros por tais forças que não se movem para longe de suas posições normais, enquanto na molécula polar os elétrons, sendo mais móveis, movem-se separando a molécula em uma parte positiva e uma negativa." Ele reconhece que a polaridade pode variar amplamente quando diz: "uma molécula, ou mesmo parte de uma molécula, pode passar de um tipo extremo ao outro, não por uma variação súbita e descontínua, mas por gradações imperceptíveis."

Entre as publicações de Lewis de 1913 e 1916, e pouco antes desta última, saíra publicado um importante artigo do físico alemão Walther Kossel (1888-1956) na revista Annalen der Physik ${ }^{29}$, sob a influência das descobertas recentes de Rutherford, Bohr e da escola alemã de física, em que Kossel discute a formação de moléculas em termos da estrutura atômica. Kossel trata longamente da formação de compostos polares (i.e., iônicos) pela perda ou ganho de elétrons e a consequente formação de espécies carregadas eletricamente que se atraem, estabilizando as estruturas dos produtos. No artigo de Lewis de 1916, como ele já havia começado a fazer em 1913, a questão é bastante ampliada, abrangendo todos os tipos de ligações, como está citado acima, quando ele se refere aos compostos iônicos, por ele chamados de polares, aos compostos moleculares, chamados de não-polares, e às substâncias metálicas.

Na seção intitulada "O átomo cúbico" do artigo de 1916, Lewis se refere ao memorando privado usado por ele desde 1902 e no qual ele havia proposto o que chamara de "teoria do átomo cúbico." O assunto só veio a público a partir do artigo de 1916. Este é o famoso conceito pelo qual os elétrons de valência de um átomo se distribuem pelos vértices de um cubo, variando de 0 a 8 . Sua teoria é apresentada na forma de 6 postulados, que são:

1. Em cada átomo há um "caroço" (kernel) essencial que permanece inalterado em todas as mudanças químicas ordinárias e que possui um excesso de cargas positivas correspondendo em número ao número ordinal do grupo na tabela periódica ao qual pertence o elemento.

2. O átomo é composto do caroço e de um átomo externo ou camada que, no caso do átomo neutro, contém elétrons negativos em número igual ao excesso de cargas positivas no caroço, mas o número de elétrons na camada pode variar durante a transformação química entre 0 e 8.

3. O átomo tende a ter um número par de elétrons na camada (de valência), e especialmente a ter 8 elétrons que são normalmente arranjados simetricamente nos 8 vértices de um cubo.

4. Duas camadas atômicas são mutuamente interpenetráveis.

5. Os elétrons podem ordinariamente passar prontamente de uma posição na camada externa para outra. Não obstante, eles são mantidos em posição por limitações mais ou menos rígidas, $e$ essas posições e a grandeza das limitações são determinadas pela natureza do átomo e dos outros átomos que estejam combinados com o primeiro.

6. As forças elétricas entre partículas que estejam muito próximas não obedecem à simples lei do inverso dos quadrados que prevalece em distâncias maiores.

Em seguida ele passa a discutir cada um dos postulados, que será aqui resumido:

1. O primeiro postulado trata das duas partes do átomo que se relacionam com o átomo de Thomson. Como o caroço é a parte interna que não se altera numa reação, ele pode ser representado pelo símbolo do elemento, por exemplo Li.

2. O postulado 2 deve ser discutido juntamente com o postulado 4 . Aplicando ao conceito de oxidação e redução, pode-se dizer que a redução é um aumento e a oxidação um decréscimo no número de elétrons na camada externa de um elemento. Assim, o cloro tem 8 elétrons nessa camada nos cloretos, 6 nos hipocloritos, 4 nos cloritos 2 nos cloratos e zero nos percloratos.
3. Ao discutir o postulado 3 ele apresenta o caso, considerado excepcional, das substâncias contendo átomos com número ímpar de elétrons, como $\mathrm{NO}, \mathrm{NO}_{2} \mathrm{ou} \mathrm{ClO}_{2}$. Estas são moléculas reativas que, em presença de um meio polar tendem a reagir, como, por exemplo, $\mathrm{NO}_{2}$, que em água forma ácido nítrico e ácido nitroso.

4. Neste postulado ele levanta o argumento de que, sendo as camadas interpenetráveis, "um elétron pode formar uma parte da camada de dois átomos diferentes e não se pode dizer que pertença a qualquer um deles exclusivamente. Daí é em geral impossível dizer que um elemento num composto tenha, durante uma mudança química, sido oxidado ou reduzido, e que um outro elemento não tenha sofrido uma tal variação; é só quando abordamos substâncias do tipo completamente polar que tais distinções se tornam menos e menos ambíguas".

5. Este postulado se baseia na inexistência de isômeros intra-atômicos, em que num dado tempo os elétrons da camada externa pudessem ocupar um conjunto de posições e noutro tempo um conjunto diferente de posições.

6. Aqui Lewis parece estabelecer um limite de aplicabilidade da Lei de Coulomb, que só seria válida para distâncias superiores àquelas existentes nas ligações entre átomos. Esta premissa era necessária para que ele pudesse justificar o conceito de par de elétrons na formação de ligações. Ele se inspirou provavelmente na ideia de Bohr, expressa em seus trabalhos de 1913, de que em seu modelo atômico as leis do eletromagnetismo clássico também eram violadas. ${ }^{30}$

Ao discutir a ligação entre dois átomos, diz: "para expressar essa ideia de união química em símbolos eu sugeriria o uso de dois pontos, arranjados de forma a representar os dois elétrons que agem como as conexões entre os dois átomos. Deste modo podemos escrever $\mathrm{Cl}_{2}$ como $\mathrm{Cl}$ : $\mathrm{Cl}$ ".

$\mathrm{O}$ artigo de Lewis é bastante extenso e ele discorre longamente sobre vários tópicos ligados a seus conceitos, dando um grande número de exemplos para ilustrar suas ideias.

O terceiro artigo, de 1923, é o texto de uma conferência pronunciada por ele na Faraday Society de Londres e publicada naquele mesmo ano nas Trans. Far. Soc. ${ }^{31}$ Seu título é "Conferência Introdutória: Valência e o Elétron". Este artigo resume e clarifica suas ideias, como quando ele diz, referindo-se aos compostos orgânicos: "eu propus representar toda ligação como um par de elétrons ligados conjuntamente por dois átomos". Na seção intitulada " $O$ Par de Elétrons como a Ligação Química" ele antecipa a questão da influência dos pares de elétrons não ligantes na geometria das moléculas: "Estejamos lidando com compostos orgânicos ou inorgânicos, a ligação química é sempre o par de elétrons. Por mais importante que seja o par de elétrons para a teoria total da valência, deve-se observar que tal par não é fundamentalmente diferente de outros pares que não formam ligações." Em seguida, usando o termo "octeto", cunhado por Langmuir em 1919, ele discute a sequência $\mathrm{N}^{3-},[\mathrm{NH}]^{2-},\left[\mathrm{NH}_{2}\right], \mathrm{NH}_{3}$ e $\left[\mathrm{NH}_{4}\right]^{+}$, mostrando como a estrutura do octeto do nitrogênio sofrerá distorções pela presença desigual de elétrons ou átomos.

No período entre seus dois últimos artigos, Irving Langmuir havia publicado em J. Amer. Chem. Soc., em 1919, um longo artigo intitulado "O Arranjo de Elétrons nos Átomos e Moléculas". ${ }^{32}$ Além de organizar e avançar nas ideias de Lewis, Langmuir introduz em seu artigo duas novas expressões, que são usadas até hoje. A primeira aparece quando, ao discutir o arranjo cúbico dos elétrons, de acordo com Lewis, ele diz: "chamaremos este grupo estável de 8 elétrons de octeto". Mais adiante, sob o título "Valência, Número de Coordenação e Covalência”, escreve Langmuir: "denotaremos pelo termo covalência" as ligações envolvendo compartilhamento de elétrons. Langmuir foi o grande popularizador da teoria de Lewis, de tal sorte que ela 
passou a ser conhecida por muitos como teoria de Lewis-Langmuir, para grande desgosto de Lewis. ${ }^{33}$

Durante o ano de 1916, quando publicou seu artigo mais famoso sobre as ligações químicas, Lewis manteve extensa correspondência com Niels Bohr, e convidou-o a passar um semestre em Berkeley para dar um curso sobre a estrutura atômica e molecular. Infelizmente Bohr não pôde atender ao convite. ${ }^{33}$

Lewis, todavia, não se cansava de preocupar-se com o que se chamava o átomo dos físicos e o átomo dos químicos. Para um químico tão próximo da física como Lewis, este era um problema que precisava de uma solução. $\mathrm{O}$ aparentemente insolúvel problema do compartilhamento eletrônico foi finalmente equacionado em 1925 com o surgimento do Princípio da Exclusão de Pauli e do conceito de spin eletrônico, que permitiram racionalizar as ideias de Lewis de um ponto de vista físico. ${ }^{33} \mathrm{O}$ próprio Lewis escreveu em seu famoso artigo de 1938 sobre ácidos e bases, mostrando uma aguda percepção dos problemas em jogo:

"quando a ideia de emparelhamento de elétrons estava sendo desenvolvida no início, era necessário tirar algumas conclusões a respeito da estrutura eletrônica apenas a partir do comportamento químico das substâncias. A física teórica daquela época não oferecia qualquer ajuda, já que havia sido mostrado que a suposição de meras forças coulombianas era incompativel com a existência de quaisquer átomos ou moléculas estáveis compostos por núcleos positivos e elétrons.

Mais recentemente, e em grande parte depois de eu ter escrito sobre este assunto há quinze anos, as condições mudaram radicalmente. Por um lado, o desenvolvimento de inúmeros métodos precisos de medida forneceu informações bastante exatas sobre o formato e o tamanho de muitas moléculas. Por outro, a mecânica quântica revolucionou nossa ideia sobre as interações de partículas materiais, especialmente em sistemas de pequeno tamanho. É interessante, portanto, constatar que as conclusões que haviam sido baseadas em observações puramente químicas, e em boa parte qualitativas, retiveram sua validade, e em muitos casos foram fortalecidas pelo novo conhecimento.

O princípio de Pauli deu a primeira interpretação física do emparelhamento de elétrons, e Heitler e London conseguiram deduzir a ligação por par de elétrons a partir da mecânica quântica. É verdade que a velha ideia da localização exata dos elétrons numa molécula teve que ser abandonada. Em seu lugar temos a mais nebulosa "nuvem eletrônica". Todavia, a parte mais densa dessa nuvem, que representa a região em que o elétron é predominantemente mais provável de estar, coincide, no caso de todos os compostos do tipo mais completamente saturado, com as posições dos elétrons exigidas pelas fórmulas químicas. Em moléculas insaturadas em que a "nuvem eletrônica" é menos definitivamente localizada, muitas vezes encontramos que as propriedades não podem ser bem representadas por uma única fórmula química.

Enquanto se provou finalmente ser possível reconciliar a mecânica quântica com a exigência química de completa simetria das quatro ligações no metano, há uma exigência química que o desenvolvimento da mecânica quântica ainda não satisfez. Trata-se de um elemento essencial na teoria original do octeto, não apenas que um átomo ligado a quatro outros tivesse os pares eletrônicos em posições tetraédricas, mas que isto seria ainda verdadeiro mesmo que um ou mais dos pares eletrônicos não fossem usados nas ligações. Disso se deduziu que a água não teria uma estrutura linear nem a amônia uma estrutura plana, $e$ que a posição de um par não-ligante estaria situada no vértice de um tetraedro, de forma a produzir isomeria óptica, como se achou realmente nos compostos de sulfônio. Mesmo para a molécula mais simples a aplicação da mecânica quântica é por demais dificil para qualquer coisa mais que um tratamento aproximado. Entretanto, se um tratamento exato um dia se tornar possível, podemos estar seguros que ele mostrará no caso de uma molécula como a de amônia não apenas a concentração da "nuvem eletrônica" representando cada uma das ligações aos três átomos de hidrogênio, mas também uma quarta concentração na forma de uma protuberância na quarta posição tetraédrica, e que esta projeção devida ao par de elétrons não-ligados é a entidade característica das moléculas básicas." 34

Em 1923 Lewis publicou seu famoso livro "Valência e a estrutura de átomos e moléculas", já mencionado acima, no qual ele discorre mais demoradamente sobre suas ideias relativas às ligações químicas.

Uma consequência importante do conceito de ligação por par de elétrons é o conceito de ácidos e bases de Lewis, que muitos, equivocadamente, chamam de "teoria de ácidos e bases de Lewis", quando se trata de um conceito, ou definição, que é muito diferente de uma teoria. A mesma observação se pode fazer com relação a outros conceitos de ácido e base, como o de Arrhenius, do século XIX, que às vezes também é chamado de teoria, quando na realidade é um conceito derivado da teoria da dissociação eletrolítica de Arrhenius.

Lewis viria a dedicar-se a estudar o conceito de ácidos e bases já no final de sua carreira, sobretudo em seu artigo de 1938 publicado pelo J. Franklin Institute. ${ }^{34}$ Lewis aqui foi de uma engenhosidade e originalidade incríveis. As definições precedentes de ácidos e bases pressupunham um meio em que as interações ocorriam (água, no caso da definição de Arrhenius, em que os ácidos podiam doar $\mathrm{H}^{+}$, e as bases podiam doar $\mathrm{OH}^{-}$, sempre em meio aquoso), ou a presença de uma dada espécie química (íon hidrogênio que podia ser doado pelos ácidos, ou recebido pelas bases, na definição de Brønsted-Lowry). A definição de Lewis era muito mais abrangente e universal, pois levava em conta um componente de toda a matéria, os elétrons, que podiam ser doados pelas bases e recebidos pelos ácidos. A definição de acidez e basicidade de Lewis foi de certa forma uma enorme propulsora do progresso no estudo de mecanismos de reação de compostos orgânicos. Como a maioria das reações orgânicas não se passa em meio aquoso, as definições anteriores só tinham uma aplicabilidade muito restrita na química orgânica.

O aspecto mais surpreendente da Teoria de Ligação Química de Lewis é o fato de ela ter sido formulada 10 anos antes do surgimento da mecânica quântica, e ser ainda atual em muitos de seus aspectos. Se atentarmos para usar "densidade eletrônica" no lugar de usar exclusivamente "par de elétrons", temos aí uma atualização das ideias de Lewis, que se mostram resistentes ao tempo dessa maneira. O que se chamava no século XVIII "afinidade eletiva" deu origem ao conceito muito mais preciso de "ligação química". Um dos maiores admiradores de Lewis no século XX foi Linus Pauling, que dedicou-lhe seu livro mais conhecido, The Nature of the Chemical Bond $^{35}$, de 1939. Em artigo posterior, assim disse Pauling: "Quando penso na história da ligação química, pergunto-me por que algumas das descobertas feitas na era da mecânica quântica da década de 1930 não foram descobertas antes. A escala de eletronegatividades dos elementos é um exemplo. Ela foi formulada em 1933... A ideia básica, atribuída à mecânica quântica em 1933, é que o caráter iônico parcial de uma ligação a torna mais estável, com energia mais baixa do que uma ligação covalente pura entre átomos desiguais. Esta ideia não é derivada da mecânica quântica." 19 Pauling continua dizendo que Langmuir formulara o princípio da eletroneutralidade, mas fizera pouco caso dele, e Lewis o ignorou. Foi por essa razão que o conceito e a escala de eletronegatividades levaram bem mais tempo para surgir. ${ }^{19}$ 


\section{CONCLUSÃO}

As ideias e conceitos apresentados aqui o foram de forma bastante sucinta com o intuito de salientar o papel central de Lewis no desenvolvimento da química no século XX. Sua obra foi tão fundamental que marcou de forma indelével boa parte do que se seguiu, como o próprio Pauling reconhece. Poucos são os cientistas a quem se pode atribuir um papel tão marcante no curso da ciência. Lewis permanece como um desses poucos.

\section{REFERÊNCIAS}

1. Tosi, L., Quím. Nova 1989, 12, 33.

2. Filgueiras, C. A. L., Quím. Nova 1995, 18, 219-224.

3. Filgueiras, C. A. L., Lavoisier - o estabelecimento da química moderna, Odysseus, São Paulo, 2002, pp. 1-197.

4. Filgueiras, C. A.L., Química Nova na Escola 2004, 20, 38.

5. Shaik, S., J. Comput. Chem. 2006, $28,51$.

6. Tiernan, N. F., J. Chem. Educ. 1985, 62, 569.

7. Hildebrand, J. H., Biog. Memoirs Nat. Acad. Sci. (U.S.) 1958, 31, 208.

8. Gonçalves-Maia, R., Lewis, Editora Livraria da Física, São Paulo, 2016, $1-85$.

9. Kasha, M., J. Chem. Educ., 1984, 61, 204.

10. James, L. K., ed., Nobel Laureates in Chemistry 1901-1992, American Chemical Society and the Chemical Heritage Foundation, Washington, 1993, pp. 100-107.

11. Richards, T. W., e Lewis, G.N., Proc. Amer. Acad. Arts and Sciences, 1898, 34, 87.

12. Lewis, G. N., Valence and the Structure of Atoms and Molecules, Dover Publications, [1923] 1966, N. York, pp. 29-30.

13. Idem, ibid., p. 1.

14. Lewis, G. N., e Randall, M., Thermodynamics and the Free Energy of Chemical Substances, 1923, McGraw-Hill, N. York.
15. Coffey, P., Cathedrals of Science - the Personalities and Rivalries that made Modern Chemistry, Oxford University Press, N. York, 2008, p. 303.

16. Gillespie, R. J., Robinson, E. A., J. Comput. Chem. 2006, $28,87$.

17. Coffey, P., op. cit., p. 300.

18. Lewis, G. N., J. Amer. Chem. Soc. 1924, 46, 2027.

19. Pauling, L., J. Chem. Ed. 1984, 61, 261.

20. Cacace, F., de Petris, G., Troiani, A., Angew. Chem., Int. Ed. 2001, 40, 4062.

21. Gadzhiev, O. B., Ignatov, S. K., Kulikov, M. Y., Feigin, A. M., Razuvaev, A. G., Sennikov, P. G., Schrems, O., J. Chem. Theory Comput., 2013, 9 , 247.

22. Prasad, O., Sinha, L., Misra, N., Narayan, V., Srivastava, R. K., Mishra, H. N., Der Pharma Chemica, 2009, 1, 79.

23. Lewis, G. N., a) Technol. Quart. 1908, 21, 212; b) Phil. Mag., 1908, 16, 705; c) Ann., Naturphil. 1908, 7, 429; d) Proc. Amer. Acad. 1909, 44, 711; Phil. Mag., 1909, 18, 510.

24. Lewis, G. N., The Anatomy of Science, Yale University Press, New Haven, 1926.

25. Kragh, H., arXiv preprint arXiv:2014, 1401.0293- arxiv.org.

26. Lewis, G. N., Nature 1926, 118, 874.

27. Lewis, G. N., J. Amer. Chem. Soc. 1913, 35, 1448.

28. Lewis, G. N., J. Amer. Chem. Soc. 1916, 38, 762.

29. a) Kossel, W., Ann. Phys. 1916, 49, 229; b) Leicester, H. M., ed., Sourcebook in Chemistry 1900-1950, Harvard Un. Press, Cambridge, 1968.

30. Braga, J. P., Filgueiras, C. A. L., Quím. Nova 2013, 36, 1073.

31. Lewis, Trans. Far. Soc. 1923, 19, 452.

32. Langmuir, I., J. Amer. Chem. Soc. 1919, 41, 868.

33. Simões, A., J. Comput. Chem., 2006, 28, 62.

34. Lewis, G. N., J. Franklin Institute 1938, 118, 293.

35. Pauling, L., The Nature of the Chemical Bond and the Structure of Molecules and Crystals, Cornell University Press, Ithaca, [1939], $3^{\text {rd }}$ ed., 1960. 